University of Nebraska - Lincoln

DigitalCommons@University of Nebraska - Lincoln

Sociology Department, Faculty Publications

Sociology, Department of

2011

\title{
Pregnancy and Intimate Partner Violence: Risk Factors, Severity, and Health Effects
}

\author{
Douglas A. Brownridge \\ University of Manitoba, brownrid@cc.umanitoba.ca \\ Tamara L. Tallieu \\ University of Manitoba \\ Kimberly A. Tyler \\ University of Nebraska-Lincoln, kim@ktresearch.net \\ Agnes Tiwari \\ University of Hong Kong \\ Ko Ling Chan \\ University of Hong Kong \\ See next page for additional authors
}

Follow this and additional works at: https://digitalcommons.unl.edu/sociologyfacpub

Part of the Sociology Commons

Brownridge, Douglas A.; Tallieu, Tamara L.; Tyler, Kimberly A.; Tiwari, Agnes; Chan, Ko Ling; and Santos, Susy C., "Pregnancy and Intimate Partner Violence: Risk Factors, Severity, and Health Effects" (2011). Sociology Department, Faculty Publications. 154.

https://digitalcommons.unl.edu/sociologyfacpub/154

This Article is brought to you for free and open access by the Sociology, Department of at DigitalCommons@University of Nebraska - Lincoln. It has been accepted for inclusion in Sociology Department, Faculty Publications by an authorized administrator of DigitalCommons@University of Nebraska - Lincoln. 


\section{Authors}

Douglas A. Brownridge, Tamara L. Tallieu, Kimberly A. Tyler, Agnes Tiwari, Ko Ling Chan, and Susy C. Santos 


\title{
Pregnancy and Intimate Partner Violence: Risk Factors, Severity, and Health Effects
}

\author{
Douglas A. Brownridge, ' Tamara L. Taillieu,' Kimberly A. Tyler, ${ }^{2}$ \\ Agnes Tiwari, ${ }^{3}$ Ko Ling Chan, ${ }^{3}$ and Susy C. Santos ${ }^{4}$
}

I. University of Manitoba, Winnipeg, Manitoba, Canada

2. University of Nebraska-Lincoln

3. University of Hong Kong, Hong Kong

4.Victoria General Hospital,Winnipeg, Manitoba, Canada

Corresponding author - D.A. Brownridge, Department of Family Social Sciences, University of Manitoba,Winnipeg, Manitoba, Canada R3T 2N2; email Douglas_Brownridge@umanitoba.ca

\begin{abstract}
The current study compares female victims of intimate partner violence (IPV) who were and were not victimized during pregnancy.Victims of pregnancy violence are more likely to report having experienced all forms of violence, particularly severe forms, and have higher odds of experiencing several postviolence indicators of severity and adverse health consequences. The significance of predictors disappears in a post hoc analysis controlling for proxies of battering behavior (i.e., repeated and severe violence), suggesting that victims who experience violence during pregnancy may be more likely to be in a current intimate relationship with an abuser who inflicts repeated and severe IPV.
\end{abstract}

Keywords: abuse, pregnancy, violence, women

Violence against women is an important societal issue; it is estimated that about one in five women have ever experienced violence from a current or former intimate partner (Tjaden \& Thoennes, 2000). Pregnancy may be a time of unique vulnerability to intimate partner violence (IPV) victimization because of changes in women's physical, social, emotional, and economic needs during pregnancy (Noel \& Yam, 1992). Past research has reported a wide range of prevalence rates of pregnancy violence $(0.9 \%-20.1 \%$; Gazmararian et al., 1996). However, the ma- 
jority of studies have found prevalence rates ranging from 3.9\% to 8.3\% (Gazmararian et al., 1996; Helton, McFarlane, \& Anderson, 1987; Martin, Mackie, Kupper, Buescher, \& Moracco, 2001; Muhajarine \& D'Arcy, 1999; Saltzman, Johnson, Gilbert, \& Goodwin, 2003; Stewart \& Cecutti, 1993). Although the true prevalence of IPV during pregnancy is unclear, based on past research it is evident that a substantial minority of women experience violence during pregnancy. Moreover, pregnancy violence often continues into the postpartum period (Martin et al., 2001; Mezey \& Bewley, 1997; Widding Hedin, 2000). To improve the health of pregnant women and their infants, it is important that research investigates the risk factors for violence against women during pregnancy, the nature and patterns of violence experienced by pregnant women, and the consequences of such violence. The purposes of the current study are to (a) investigate risk factors relevant to the understanding of violence against pregnant women, (b) investigate indicators of severity of violence against pregnant women, and (c) investigate differences in postviolence health effects for victims who do and do not experience violence during pregnancy.

\section{Risk Factors for Violence During Pregnancy}

Several studies have attempted to identify risk factors associated with experiencing violence during pregnancy (e.g., Bohn, Tebben, \& Campbell, 2004; Dunn \& Oths, 2004; Lipsky, Holt, Easterling, \& Critchlow, 2005; Muhajarine \& D'Arcy, 1999; Saltzman et al., 2003; Stewart \& Cecutti, 1993). However, all of these studies compared women who were abused during pregnancy to nonabused pregnant women. To further our understanding of risk factors for experiencing violence during pregnancy, it may also be useful to investigate factors that differentiate female victims of intimate partner violence (IPV) who were and were not victimized during pregnancy. This will allow us to shed light on unique aspects of pregnancy violence. In addition, the current study examines risk factors using a nationally representative sample. Although some research on risk factors of pregnancy violence has used population-based samples, these studies possessed significant limitations. A number of risk factors were assessed in a national probability sample investigating the relationship between alcohol and family violence (ethnicity, education, life stressors, and wife assault/violence history). However, this analysis was confined to investigating differences between White and Hispanic women (Jasinski \& Kaufman Kantor, 2001). Although Saltzman et al. employed a population-based sample, their analyses were confined to bivariate tests of association. Gelles (1988) used a nationally representative sample of more than 6,000 American families to investigate differences in rates of overall, minor, and severe violence among pregnant and nonpregnant women. However, this study focused only on the risk factor of age as a possible explanation for higher rates of violence against pregnant women. Jasinski (2001) longitudinally studied pregnancy violence using national probability data, but this investigation did not focus on risk factors per se.

A number of risk factors relevant to understanding the risk of violence during pregnancy were available in the data used in the current study. The remainder of this section identifies risk factors for pregnancy violence that were avail- 
able in the data and provides a brief overview of past research on the relationship between each risk factor and pregnancy violence.

\section{Age}

A number of studies have shown that a relationship exists between young age and an increased risk of violence during pregnancy (Bohn et al., 2004; Dunn \& Oths, 2004; Heaman, 2005; Janssen et al., 2003; Muhajarine \& D'Arcy, 1999; Rådestad, Rubertson, Ebling, \& Hildingsson, 2004; Saltzman et al., 2003; Stewart \& Cecutti, 1993). However, this association often becomes nonsignificant in multivariate analyses (e.g., Bohn et al., 2004; Dunn \& Oths, 2004; Gelles, 1988; Heamen, 2005; Janssen et al., 2003; Muhajarine \& D'Arcy, 1999). It is also noteworthy that most of these studies involved clinic- or hospital- based samples rather than population-based samples. The only study that examined a population-based sample did not control for age using a multivariate analysis (Saltzman et al., 2003).

\section{Education}

There are inconsistent findings in the literature regarding the relationship between education and the risk for violence during pregnancy. Saltzman et al. (2003) found that women with less than 12 years of education were 4.7 times more likely to experience violence during pregnancy than women with more than 12 years of education. In a Canadian study, Stewart and Cecutti (1993) found that women failing to complete high school were at an increased risk for violence during pregnancy $(\mathrm{RR}=9.2)$ compared to those who had completed high school. However, these studies confined their analyses to bivariate tests of association and a number of other studies have found that this association disappears in adjusted models (Dunn \& Oths, 2004; Heaman, 2005; Muhajarine \& D'Arcy, 1999). Conversely, Bohn et al. (2004) reported that the only significant predictor to emerge from backward multiple logistic regression analysis was less than a high school education. In addition, it is noteworthy that none of the aforementioned studies considered the male partner's education level in their analyses.

\section{Employment}

A number of studies have investigated the association between women's employment status and the risk for violence during pregnancy, with some studies finding unemployed status to be associated with an increased risk of violence (Heaman, 2005; Stewart \& Cecutti, 1993) and others finding no association between employment status and risk for violence (Bohn et al., 2004; Dunn \& Oths, 2004; Helton et al., 1987; Leung, Leung, Lam, \& Ho, 1999; Martin et al., 2004). Most of these studies did not investigate the relationship between the male partner's employment status and the risk for violence during pregnancy (Bohn et al., 2004; Dunn \& Oths, 2004; Heaman, 2005; Helton et al., 1987; Stewart \& Cecutti, 1993). However, in the two studies that did investigate this relationship, male unemployment emerged as a significant predictor for perpetrating violence against pregnant women (Leung et al., 1999; Martin et al., 2004). 


\section{Violence in the Family of Origin}

Violence in families is often transmitted across generations. Children who witness or experience violence are more likely to perpetrate or fall victim to violence as adults compared to nonexposed children (e.g., Brownridge, 2006; Guille, 2003; Whitfield, Anda, Dube, \& Felitti, 2003). Although it is clear that violence in the family of origin has an impact on rates of adult perpetration and victimization, this relationship has not been fully explored as it relates specifically to the risk of violence during pregnancy. For instance, Sales and Murphy (2000) found that many of the drug-addicted women in their sample who experienced violence during pregnancy had histories of child abuse. However, this study was limited because it was based on a nonrepresentative, convenience sample of pregnant drug users $(n=100)$ who had experienced violence during pregnancy.

\section{Marital Status}

Single marital status may be associated with an increased risk for experiencing violence during pregnancy (Dunn \& Oths, 2004; Heaman, 2005; Janssen et al., 2003; Leung et al., 1999; Lipsky et al., 2005; Martin et al., 2004; Muhajarine \& D'Arcy, 1999; Saltzman et al., 2003; Stewart \& Cecutti, 1993). Women may be at an even greater risk if they separate or divorce while pregnant. Saltzman et al. found not only that unmarried status increased the risk of violence during pregnancy $(R R=3.8)$ but also the relative risk was even greater if the women separated or divorced while pregnant $(R R=5.3)$. No prior research has compared rates of pregnancy violence between cohabiting and marital relationships. Given an association between cohabitation and violence in general (Brownridge, 2008), it is important to explore whether cohabitation is also a risk factor for violence during pregnancy.

\section{Sexual Proprietariness}

Sexually proprietary behavior on the part of a male partner has been linked to a woman's increased risk for violence (Burch \& Gallup, 2004; Wilson, Johnson, \& Daly, 1995). Paternal uncertainty and accusations of infidelity have been associated with an increased risk of violence among pregnant women (Bacchus, Mezey, \& Bewley, 2006; Burch \& Gallup, 2004; Chambliss, 2008; Pallitto, Campbell, \& O'Campo, 2005). According to the evolutionary psychology perspective, "Unless the man constantly monitors his partner, or isolates her from other men, there is always a possibility, because of rape or infidelity, that the children she bears are not his" (Burch \& Gallup, 2004, p. 244). Male partners may develop paternal assurance tactics, such as the use of violence to establish control, to combat paternal uncertainty and increase the probability that the children he raises are his own. In a comparison of violent and nonviolent pregnant couples, women who were abused during pregnancy were more likely to be carrying a child that was not her current partner's biological child (Martin et al., 2004). In a sample of convicted spouse abusers, men with pregnant partners evidenced significantly higher sex- 
ual jealousy scores than men whose partners were not pregnant (Burch \& Gallup, 2004). McFarlane, Campbell, Sharps, and Watson (2002) found that women who were abused during pregnancy were stalked at a significantly greater rate than abused women who were not abused during pregnancy. In addition, pregnancy has been linked to an increased sense of ownership over the woman by her male partner (Sales \& Murphy, 2000). Thus, sexual proprietariness, in terms of jealousy and possessiveness, may be especially relevant for understanding violence against pregnant women.

\section{Patriarchal Dominance}

Patriarchal domination has been linked to an increased risk of violence against women (e.g., Smith, 1990). However, there is little research on the impact of patriarchal dominance on the risk of violence during pregnancy. Violence may stem from a man's need to enforce power and control in his relationship, and pregnancy may have a significant impact on the power dynamics of a relationship (Bacchus et al., 2006; Pallitto et al., 2005). Pregnancy may symbolize a time when the woman assumes more control over her own body and may represent a degree of independence from her male partner; violence against the pregnant partner may represent a male partner's attempt to reassert control (Bacchus et al., 2006). As well, abusers tend to hold more conventional sex role attitudes, and pregnancy-related factors (such as reduced mobility, increased tiredness, preoccupation with pregnancy, blocked free access to a woman's body, and a lack of emotional availability) may interfere with a woman's ability to perform her traditional role as homemaker/ caretaker (Bacchus et al., 2006; Jasinski, 2001; Noel \& Yam, 1992; Pallitto et al., 2005), which may lead to an increased risk of violence. Pregnancy is also associated with increased financial pressures and may increase a woman's financial dependency on her male partner (Bacchus et al., 2006; Noel \& Yam, 1992; Pallitto et al., 2005; Sales \& Murphy, 2000). Financial control by restricting access to money is a means to maintain control in a relationship (Pallitto et al., 2005), and this type of control has been reported by a number of women who have been abused during pregnancy (Bacchus et al., 2006; Pulido, 2001; Sales \& Murphy, 2000). Although there is some indication that an association between patriarchal dominance and the risk of violence during pregnancy exists, most evidence regarding this relationship involves qualitative, retrospective data from women who have experienced violence while pregnant without the benefit of a comparison group of women who have not experienced violence during pregnancy. Indeed, the relationship between patriarchal domination and risk for violence during pregnancy has yet to be assessed in a nationally representative sample of women experiencing violence.

\section{Social Isolation}

Many women who are abused during pregnancy have reported that their partners attempt to socially isolate them from family, friends, and other social support systems (Bacchus et al., 2006; Noel \& Yam, 1992; Pulido \& Gupta, 2002; 
Sales \& Murphy, 2000). The existence of a social support network has been identified as a protective factor for violence during pregnancy. For example, Muhajarine and D'Arcy (1999) found that the greater number of people with whom pregnant women could talk about personal and private issues and with whom they could get together and have fun was associated with a significant decrease in pregnant women's risk for violence. Bacchus et al. reported that abused pregnant women were isolated from family and friends and that their partners were jealous of other close relationships. These women were often prevented from going out, followed by partners when they were out, and interrogated upon return. Conversely, Dunn and Oths (2004) found no significant differences in the social support networks of abused and nonabused pregnant women, as measured by the mean number of individuals in the social network.

\section{Verbal Abuse}

The vast majority of women reporting physical violence during pregnancy are also victims of verbal abuse and psychological aggression (Bacchus et al., 2006; Campbell, 2002; Martin et al., 2004; Sales \& Murphy, 2000; Stewart \& Cecutti, 1993; Valladares, Ellsberg, Peña, Hoberg, \& Persson, 2002). In fact, psychological abuse may be the predominant form of abuse during pregnancy in some cultures. Studies investigating abuse during pregnancy in China have consistently found that emotional abuse and threats of violence are the most prevalent forms of abuse experienced by Chinese pregnant women (Leung, Leung, Chan, \& Ho, 2002; Leung et al., 1999; Leung, Wong, Leung, \& Ho, 2001; Tiwari et al., 2005). Psychological abuse acts as a means to establish control in violent relationships and often creates feelings of fear, insecurity, worthlessness, and dependency in victims (Bacchus et al., 2006; Sales \& Murphy, 2000). Women who are abused during pregnancy experience higher rates of psychological aggression both before and during pregnancy compared to nonabused women (Martin et al., 2004). Moreover, research indicates that verbal abuse may be associated with an increased risk of physical and/or sexual violence during pregnancy (Bacchus et al., 2006; Martin et al., 2004; Sales \& Murphy, 2000).

\section{Rural/Urban Residence}

The potential relationship between rural/urban residence and the risk for violence during pregnancy has not been fully explored in the literature. Women living in rural areas may be more likely than those in urban areas to have limited access to both health care and social services (Noel \& Yam, 1992), which in turn may increase their risk of victimization. However, in a study investigating risk factors associated with the risk of being hit in the year after childbirth, Rådestad et al. (2004) found no significant differences in the risk for violence related to residential area (large city, mid-sized city, small city, or rural area). In addition, Bullock, Mears, Woodcock, and Record (2001) found that $13.9 \%$ of the rural women investigated experienced physical violence during pregnancy, which is similar to prevalence rates found in urban hospital-based studies. On the other hand, in 
a study investigating the prevalence of IPV in mainland China, $\mathrm{Xu}$ et al. (2005) found that the risk for violence was greater if women grew up in a rural area, regardless of whether they stayed or migrated, compared to an urban or suburban area. In addition, male partners who were raised in a rural area were more likely to perpetrate violence in adulthood. However, this study did not assess the risk of violence during pregnancy specifically. There is some indication that the rural/urban residence distinction may be especially salient in understanding the risk for violence in the Canadian context; Aboriginal women are at greater risk for violence during pregnancy compared to non-Aboriginal women (Heaman, 2005; Janssen et al., 2003; Muhajarine \& D'Arcy, 1999; Stewart \& Cecutti, 1993), and many Aboriginal women live in isolated rural communities.

\section{Heavy Drinking by Partner}

Although a number of studies have documented that a relationship exists between women's alcohol use and the risk for experiencing violence during pregnancy (Datner, Wiebe, Brensinger, \& Nelson, 2007; Heaman, 2005; Janssen et al., 2003; Lipsky et al., 2005; McFarlane, Parker, \& Soeken, 1996; Pallitto et al., 2005; Stewart \& Cecutti, 1993), few studies have investigated how heavy drinking by the male partner relates to the risk of perpetrating violence against a pregnant partner. Muhajarine and D'Arcy (1999) found that women who had a partner with a drinking problem were more than 3 times as likely to be abused during pregnancy compared to women whose partner did not have a drinking problem. In a small qualitative study of victims of violence during pregnancy, many of the respondents reported being assaulted when their partner was intoxicated and that the violence escalated when their partners were drunk (Bacchus et al., 2006). However, it is important to note that violence was not confined only to periods of intoxication, and all of the women also reported experiencing violence when their partner was sober.

\section{Severity of Pregnancy Violence}

Extant research suggests that women who experience violence during pregnancy may be more likely than those who do not experience violence while pregnant to be victims of severe violence. In a sample of men convicted of spousal assault, male-reported frequency and severity of violence scores and injury frequency and severity scores were almost double for violence directed at partners who were pregnant compared to nonpregnant partners; these scores were even higher for violence directed at previous pregnant partners compared to previous nonpregnant partners (Burch \& Gallup, 2004). As well, Stewart and Cecutti (1993) reported that $66.7 \%$ of women abused during pregnancy sought medical treatment for the abuse. Pregnant women have also been found to be more likely to experience attempted and completed femicide (Campbell, García-Moreno, \& Sharps, 2004; Martin, Macy, Sullivan, \& Magee, 2007; McFarlane et al., 2002), with the odds of becoming a victim of femicide 3 times higher for those experiencing violence during pregnancy (McFarlane et al., 2002). 


\section{Health Effects of Violence Experienced During Pregnancy}

Women experiencing violence during pregnancy are subject to a number of detrimental physical and mental health outcomes.

\section{Physical Health Outcomes}

Victims of IPV are more likely to report negative physical health effects such as poor health status, poor quality of life, and increased use of health care services, and IPV remains one of the leading causes of injury in women (Campbell, 2002). Pregnant victims of violence report being kicked, punched, thrown down stairs, threatened with knives, choked, scalded, pushed out of moving cars, and having objects thrown at them (Bacchus et al., 2006) along with a number of violence-related injuries, including cuts, bruises, fractures, concussions, dental injuries, stab wounds, vaginal bleeding, and persistent headaches as a result of the abuse they experience (Bacchus et al., 2006; Stewart \& Cecutti, 1993). It has been estimated that $10 \%$ of hospitalizations due to injury in pregnancy are the result of intentional injuries inflicted upon the pregnant woman (Chambliss, 2008).

\section{Mental Health Outcomes}

Abuse during pregnancy has been linked to depression, both during pregnancy (Chambliss, 2008; Dunn \& Oths, 2004; Martin et al., 2006; Pallitto et al., 2005) and in the postpartum period (Gross, Wells, Radigan-Garcia, \& Dietz, 2002; Widding Hedin, 2000). Women abused during pregnancy are 2.5 times more likely to report being depressed (Dunn \& Oths, 2004) and to evidence clinically relevant levels of depression (Martin et al., 2006) compared to women not abused during pregnancy. Martin et al. found that any level of physical or sexual assault experienced during pregnancy was associated with increased levels of depression.

In addition to depression, women who are abused during pregnancy report various other manifestations of psychopathology, including increased distress (others do not understand feelings, worry that needs will not be met, feeling alone, easily upset, believe things have gone against them) and increased problems with others (others made life unhappy/hard, people are not dependable, others have caused them pain; Casanueva \& Martin, 2007). Casanueva and Martin found that victims of violence during pregnancy were more likely to report feelings such as being fearful, misunderstood, anxious, and isolated. Abuse during pregnancy is strongly related to stress; women abused during pregnancy are more likely to report perceived stress (Valladares et al., 2002) and to report experiencing an increased number of stressful life events (Dunn \& Oths, 2004) compared to nonabused pregnant women. As well, many women who are victims of violence during pregnancy hold themselves responsible for their partner's behavior (Bacchus et al., 2006). These various manifestations of psychopathology can seriously affect both the quality of life for the new mother as well as the daily functioning of the new mothers in the postpartum period (Gross et al., 2002; Martin et al., 2006; Rådestad et al., 2004). 
Abuse during pregnancy has also been associated with significant increases in the use of tobacco, alcohol, and/or illicit drugs (Bullock et al., 2001; Datner et al., 2007; Heaman, 2005; Janssen et al., 2003; Lipsky et al., 2005; McFarlane et al., 1996; Pallitto et al., 2005; Stewart \& Cecutti, 1993). The stress associated with experiencing violence during pregnancy may lead victims to initiate or sustain the use of various substances as a coping mechanism or as a means to self-medicate (McFarlane et al., 1996; Sales \& Murphy, 2000).

\section{Materials and Methods}

\section{The Data Set}

The data employed in this study were from Statistics Canada's 1993 Violence Against Women Survey (VAWS). The VAWS resulted in a nationally representative sample of 12,300 women 18 years of age or older who completed in-depth telephone interviews concerning their experiences of physical and sexual violence since reaching the age of 16 . Among the respondents, 8,418 were in a heterosexual marital or common-law relationship at the time of the study. A total of 1,306 of these women had experienced violence from their partner. Because the current study concerned women who experienced violence in their current relationship, these 1,306 victims of violence comprised the subsample used in the analyses in the current study. Among these victims, 147 had experienced violence during pregnancy and 1,159 had not experienced violence during pregnancy. ${ }^{1}$ In all analyses the weighting scheme suggested by Statistics Canada has been followed. ${ }^{2}$

\section{Measurement}

Risk factors. The age of the respondent referred to the woman's age at the time of the interview. Respondent's and partner's education consisted of their respective education in years. Respondent's and partner's employment were each measured with a question that asked whether the respondent/her partner had worked at a business or paid job in the previous 12 months. To measure violence in the family of origin, respondents were asked whether, to the best of their knowledge, their father and father-in-law were ever violent toward their mother and mother-in-law, respectively. Marital status was derived from questions that asked the respondent about their current marital status. Because the current study concerns violence by a current intimate partner, the marital status variable contained two categories, common law and married. Partner's jealousy was measured with a single item that asked the respondent whether her partner was jealous and did not want her talking to other men. Partner's possessiveness was measured with a single item that asked respondents whether their partner demanded to know whom she was with and where she was at all times. Patriarchal dominance was measured with a single item that asked the respondent whether her partner prevented her from knowing about or having access to the family income, even if she asked. ${ }^{3}$ Social isolation was measured with a single item that asked the respondent to indicate whether her partner tried to limit her contact with family and friends. Verbal abuse consisted of a sin- 
gle item that asked the respondent whether her partner called her names to put her down or make her feel bad. Rural/urban location was derived from the postal code of the respondent's residence. Urban areas had a minimum population concentration of 1,000 and a population density of at least 400 per square kilometer based on the previous census counts. All territories outside urban areas were considered rural (Statistics Canada, 1999). Heavy drinking was measured with a single item that asked the respondent how many times in the month prior to the interview her partner had consumed five or more drinks on one occasion.

Pregnancy violence. Ten behavioral items from a modified version of the Conflict Tactics Scales (CTS; Straus, 1979) were used to identify women who experienced violence. Male partner violence against women was defined as acts of physical assault (having something thrown at you that could hurt; being pushed, grabbed, or shoved in a way that could hurt; being slapped; being hit with something that could hurt; being kicked, bit, or hit with a fist; being beaten; being choked; the threat or use of a knife or gun), physical threat (being threatened to be hit with a fist or anything else that could hurt), and sexual assault (being forced into any sexual activity by being threatened, held down, or hurt in some way) ever perpetrated by a woman's current marital or common-law partner. Hence, if respondents reported having experienced any of the aforementioned forms of violence in their current relationship they were coded as having experienced violence. Women who reported experiencing violence were then asked whether the violence happened at a time when they were pregnant. Those who indicated that they experienced violence from their current partner at a time when they were pregnant were coded as having experienced violence during pregnancy.

Postviolence indicators of severity and health effects. Respondents in the VAWS who reported having experienced intimate partner violence completed an intimate abuse report in which they were asked questions about their postviolence experiences. A number of postviolence variables were included in the current study to serve as additional indicators of the severity of the violence experienced by the respondents. ${ }^{4}$ These variables included the following: ever leaving or staying apart from the partner because he was abusive/threatening; fearing for her life; whether children ever witnessed the violence; contacting a crisis center/line, shelter/transition house, community/family center, and/or a women's center for help; whether their violent partner had ever received counseling for his violent behavior; whether the police ever found out about the violence; and whether those who did not contact the police failed to do so because of fear of their partner. The following variables were included relating to health effects that were consequences of the violence: physical injury, psychopathology, altered psyche, taking time off from everyday activities, and alcohol or drug use to cope with the violence.

\section{Methods of Analysis}

To document violence among victims who did and did not experience violence during pregnancy and investigate risk factors, bivariate comparisons were examined using cross-tabulations with Chi-square tests of significance. Logistic regression was used to calculate zero-order odds ratios and to conduct multivari- 
ate analyses. In the latter regard, logistic regression is an appropriate technique for predicting a dichotomous dependent variable from a set of independent variables. This technique also has a very simple interpretation. For a given variable it provides a ratio of the odds of violence occurring. If the value of the odds is greater than 1 the variable is positively related to violence. If it is less than 1 the variable is negatively related to violence.

\section{Results}

\section{Bivariate Comparisons}

Results showed that $11.3 \%$ of victims of violence by a current married or commonlaw partner experienced violence during pregnancy. Table 1 provides the results of the crosstabulation of the lifetime prevalence of violence by whether violence was experienced during pregnancy. Results showed that victims who experienced violence during pregnancy were significantly more likely than those who did not experience violence while pregnant to report having experienced each of the individual forms of violence. As well, the differences were greatest on some of the most severe forms of violence. Women who experienced violence during pregnancy were twice as likely to be sexually assaulted, 2.9 times more likely to be beaten up, 3.5 times more likely to have been hit with something that could hurt, and 3.7 times more likely to be kicked, bit, or hit with a fist. Table 2 provides the results of the cross-tabulations of the risk factors by whether or not violence was experienced during pregnancy. The results in Table 2 showed that there were significant differences between victims who did and did not experience violence during pregnancy on eight of the risk factors. Victims who experienced pregnancy violence were more likely to be unemployed compared to victims who did not experience pregnancy violence $(42 \%$ vs. $32 \%)$. About one third of victims of pregnancy violence reported that their father-in-law had been violent toward his wife compared to just under one quarter of victims who did not experience pregnancy violence. Partners who were violent against a pregnant woman were more likely than those who were not to be jealous ( $27 \%$ vs. $17 \%$ ) and possessive (37\% vs. $26 \%)$. Victims of pregnancy violence were more likely than victims who did not experience violence during pregnancy to report that their partners engaged in patriarchal domineering behavior ( $20 \%$ vs. $12 \%)$ and to attempt to socially isolate them $(29 \%$ vs. $15 \%)$. Forty-six percent of victims who reported having experienced IPV during pregnancy reported having also experienced verbal abuse from their partner compared to $26 \%$ of victims whose partners did not engage in violence while the respondent was pregnant. Finally, victims who experienced violence during pregnancy were slightly less likely than those who did not to report that their partner consumed alcohol heavily in the previous month.

\section{Logistic Regression}

Table 3 contains the results of the logistic regression on victims who did and did not experience pregnancy violence. Since the purpose of this analysis was to iden- 
tify risk factors that may predict pregnancy violence, only variables that were significant in the crosstabulations in Table 2 were included. ${ }^{6}$ The results in Table 3 showed that, controlling for all other variables in the model, only two variables were significant predictors of pregnancy violence. Victims who were unemployed had $54 \%$ increased odds of having experienced pregnancy violence. Victims who reported that their partner engaged in verbal abuse had $66 \%$ increased odds of reporting having experienced pregnancy violence. The Nagelkerke pseudo $R^{2}$ suggested that the variables in the model accounted for about $5 \%$ of the variance in experiences of pregnancy violence.

\section{Zero-Order Odds Ratios for Postviolence Variables}

Table 4 contains the results of the zero-order odds ratios for the postviolence indicators of severity. The results in Table 4 showed that victims who experienced pregnancy violence were significantly more likely to report variables that were indicative of having experienced more severe violence than those who did not experience pregnancy violence. Victims of pregnancy violence were twice as likely as victims who did not experience pregnancy violence to report that they left their partner at some point because of the violence and that their partners received counseling for the violence. They were 3 times more likely to report that the police found out about the violence, nearly 5 times more likely to have contacted a crisis line or community/family center, 5 times more likely to report that they had feared that their life was in danger, 6 times more likely to report that they contacted a women's center, 7 times more likely to report that they did not contact the police because they feared their partner, and 9 times more likely to report having contacted a shelter or transition house as a result of the violence.

Table 5 contains the zero-order odds ratios for the health effects of violence. The results in Table 5 showed that victims of pregnancy violence had significantly higher odds of reporting having health effects from the violence compared to those who did not experience pregnancy violence. Specifically, victims

Table I. Lifetime prevalence of each component of violence by whether violence was experienced during pregnancy (\%)

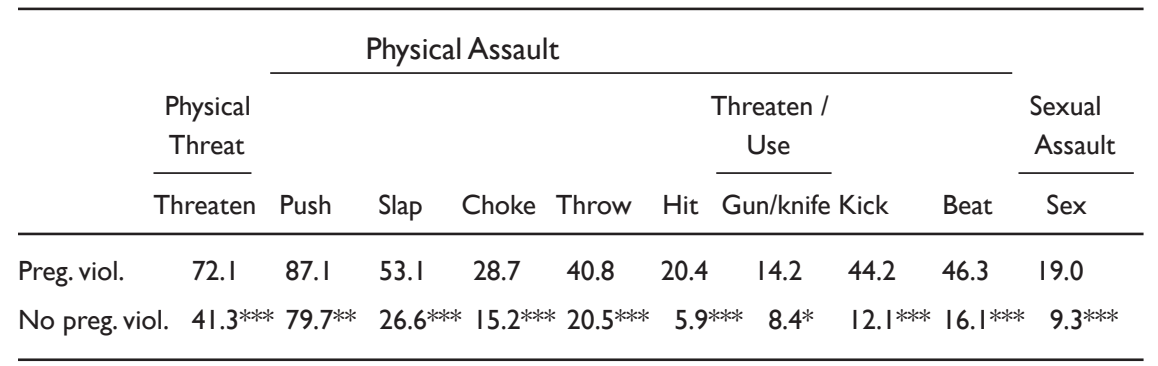

$p$ values refer to chi-square test of significance.

$* p \leq 0.10$; ** $p<0.05 ; * * * p<0.0$ I 
Table 2. Risk factors by whether or not violence was experienced during pregnancy (\%)

\begin{tabular}{|c|c|c|}
\hline \multirow{2}{*}{$\frac{\text { Risk factors }}{\text { Respondent's age }}$} & Pregnancy violence & \multirow{2}{*}{ No pregnancy violence } \\
\hline & & \\
\hline $18-34$ & 33.3 & 34.3 \\
\hline $35-54$ & 49.7 & 47.2 \\
\hline 55 or older & 17.0 & 18.6 \\
\hline \multicolumn{3}{|l|}{ Respondent's education } \\
\hline Less than high school & 32.7 & 26.1 \\
\hline High school & 26.5 & 28.3 \\
\hline Some postsecondary & 15.0 & 15.5 \\
\hline Community college diploma/ certificate & 12.2 & 15.6 \\
\hline University degree & 13.6 & 14.5 \\
\hline \multicolumn{3}{|l|}{ Partner's education } \\
\hline Less than high school & 36.6 & 34.5 \\
\hline High school & 24.1 & 25.0 \\
\hline Some postsecondary & 9.7 & 10.3 \\
\hline Community college diploma/certificate & 16.6 & 16.4 \\
\hline University degree & 13.1 & 13.8 \\
\hline \multicolumn{3}{|l|}{ Respondent's employment } \\
\hline Unemployed & 42.2 & 31.8 \\
\hline Employed & 57.8 & $68.2^{* *}$ \\
\hline \multicolumn{3}{|l|}{ Partner's employment } \\
\hline Unemployed & 18.2 & 17.8 \\
\hline Employed & 81.8 & 82.2 \\
\hline \multicolumn{3}{|l|}{ Respondent's father violent } \\
\hline Yes & 31.4 & 28.4 \\
\hline No & 68.6 & 71.6 \\
\hline \multicolumn{3}{|l|}{ Partner's father violent } \\
\hline Yes & 34.4 & 23.4 \\
\hline No & 65.6 & $76.6 * *$ \\
\hline \multicolumn{3}{|l|}{ Marital status } \\
\hline Common law & 9.5 & 14.2 \\
\hline Married & 90.5 & 85.5 \\
\hline \multicolumn{3}{|l|}{ Partner jealous } \\
\hline Yes & 26.5 & 17.3 \\
\hline No & 73.5 & $82.7^{* *}$ \\
\hline \multicolumn{3}{|l|}{ Partner possessive } \\
\hline Yes & 36.7 & 25.9 \\
\hline No & 63.3 & $74.1^{* *}$ \\
\hline \multicolumn{3}{|l|}{ Patriarchal dominance } \\
\hline Yes & 19.7 & 12.1 \\
\hline No & 80.3 & $87.9 * *$ \\
\hline \multicolumn{3}{|l|}{ Social isolation } \\
\hline Yes & 28.6 & 14.6 \\
\hline No & 71.4 & $85.4 * * *$ \\
\hline
\end{tabular}


Table 2. (continued)

\begin{tabular}{lcl}
\hline Risk factors & Pregnancy violence & No pregnancy violence \\
\hline Verbal abuse & & \\
Yes & 45.6 & 25.9 \\
No & 54.4 & $74.1^{* * *}$ \\
Rural/urban location & 31.3 & \\
Rural & 68.7 & 26.8 \\
Urban & & 73.2 \\
Partner's heavy drinking (past month) & 70.7 & 63.1 \\
None & 12.8 & 11.5 \\
Once & 8.3 & 16.8 \\
2-4 times & 8.3 & $8.7^{*}$ \\
5 or more times & & \\
\hline
\end{tabular}

$p$ values refer to chi-square tests of significance: $* p<.10 ; * * p<.05 ; * * * p<.01$

of pregnancy violence were about twice as likely to report having experienced psychopathology, an altered psyche, and/or the use of alcohol or drugs to cope with their partner's violence compared to those not having experienced violence during pregnancy. Those who had experienced violence during pregnancy were more than 3 times as likely to report having been physically injured compared to those having not experienced violence during pregnancy. Victims of pregnancy violence were more than 4 times as likely as those who did not experience pregnancy violence to report that violence caused them to take time off from everyday activities.

\section{Discussion}

Similar to rates found in past research (see Gazmararian et al., 1996), the data in the current study showed that $11.3 \%$ of victims of IPV from a current marital or common-law partner had experienced violence while pregnant. Previous research suggests that pregnancy is a protective factor for some women who experience violence from their intimate partners. Prevalence rates of violence are consistently lower during pregnancy compared to before pregnancy onset (Bohn et al., 2004; Saltzman et al., 2003) and between one third and two thirds of women who are abused prior to pregnancy report that the abuse ceased during pregnancy (Bohn et al., 2004; Janssen et al., 2003; Stewart \& Cecutti, 1993). In the current study, $88.7 \%$ of victimized women were not subject to physical and/or sexual violence during pregnancy, suggesting that pregnancy may also be a protective factor for some women in the Canadian context. Nevertheless, given the consequences associated with experiencing violence during pregnancy, the $11.3 \%$ of victims who experienced violence during pregnancy represent an important vulnerable population that is worthy of research. 
Table 3. Results of logistic regression on victims who experienced violence during pregnancy and those who did not experience violence during pregnancy

\begin{tabular}{|c|c|c|}
\hline \multirow[b]{2}{*}{ Covariates } & \multicolumn{2}{|c|}{ Pregnancy/no pregnancy violence } \\
\hline & Odds ratio & $95 \%$ confidence interval \\
\hline \multicolumn{3}{|c|}{ Respondent's employment } \\
\hline Unemployed & I.540** & $1.06 \mid-2.233$ \\
\hline Employed & 1.000 & - \\
\hline \multicolumn{3}{|l|}{ Partner jealous } \\
\hline Yes & 1.192 & $0.725-1.957$ \\
\hline No & 1.000 & - \\
\hline \multicolumn{3}{|l|}{ Partner possessive } \\
\hline Yes & 1.256 & $0.789-1.998$ \\
\hline No & 1.000 & - \\
\hline \multicolumn{3}{|l|}{ Patriarchal dominance } \\
\hline Yes & 1.221 & $0.736-2.026$ \\
\hline No & 1.000 & - \\
\hline \multicolumn{3}{|l|}{ Social isolation } \\
\hline Yes & $1.36 \mid$ & $0.82 \mid-2.258$ \\
\hline No & 1.000 & - \\
\hline \multicolumn{3}{|l|}{ Verbal abuse } \\
\hline Yes & $1.664 * *$ & $1.092-2.536$ \\
\hline No & 1.000 & - \\
\hline Heavy drinking & 0.970 & $0.926-1.016$ \\
\hline Constant & $0.074 * *$ & \\
\hline-2 Log likelihood & 818.398 & \\
\hline$x^{2}$ & $30 * * *$ & \\
\hline Nagelkerke pseudo $R^{2}$ & 0.047 & \\
\hline
\end{tabular}

$n=1,250$.

$* * p<.05 ; * * * p<.01$

In the current study, victims who had experienced violence during pregnancy were more likely to experience all forms of violence, particularly severe forms of violence. These women were not only more likely to be threatened, pushed, slapped, and hit with something that could hurt but were also significantly more likely to be choked, sexually assaulted, beaten up, and to be kicked, bit, or hit with a fist compared to victims who were not abused during pregnancy.

The results of the current study also showed that women who were abused during pregnancy had significantly higher odds of experiencing several postviolence indicators of severity. Women who were abused during pregnancy were twice as likely to leave or stay away from their partner and 9 times more likely to contact a shelter or transition house compared to victims who were not abused during pregnancy, which suggests that some of these women had considered 
Table 4. Zero-order odds ratios for postviolence indicators of severity

\begin{tabular}{|c|c|c|c|}
\hline \multirow[b]{2}{*}{ Dependent variable } & \multicolumn{3}{|c|}{ Pregnancy violence/no violence during pregnancy ${ }^{\mathrm{a}}$} \\
\hline & rder odds ratio & $95 \%$ confidence interval & $n$ \\
\hline Ever leave/stay apart & $2.25 I^{*}$ & $1.27 \mid-3.987$ & 743 \\
\hline Feared life in danger & $5.243 * *$ & $2.845-9.663$ & 741 \\
\hline Children ever witnessed incident(s) & $2.532 * *$ & I.357-4.726 & 594 \\
\hline Contacted crisis line & $4.700 *$ & $1.365-16.182$ & 743 \\
\hline Contacted shelter/transition house & $9.623 * *$ & $3.895-23.744$ & 743 \\
\hline Contacted community/family center & $4.891 *$ & $1.600-14.948$ & 743 \\
\hline Contacted women's center & $6.495^{* *}$ & $2.138-19.731$ & 743 \\
\hline Partner ever received counseling & $2.118^{*}$ & I.086-4.128 & 727 \\
\hline Police found out about incident(s) & $3.202 * *$ & $1.679-6.105$ & 741 \\
\hline Failure to contact police out of fear & $7.343 * *$ & I.883-28.634 & 629 \\
\hline
\end{tabular}

a. No violence during pregnancy is the reference category with an odds of 1.000 .

$* p<.05 ; * * p<.01$

Table 5. Zero-order odds ratios for health effects of violence

\begin{tabular}{lccc}
\hline & \multicolumn{3}{c}{ Pregnancy violence/no violence during pregnancy } \\
\cline { 2 - 4 } Dependent variable & Zero-order odds ratio & $95 \%$ confidence interval & $n$ \\
\hline Physical injury & $3.837 * *$ & $2.162-6.810$ & 743 \\
Psychopathology & $1.979 *$ & $1.116-3.510$ & 715 \\
Altered psyche & $2.369^{\mathrm{b}}$ & $1.343-4.181$ & 715 \\
Time off everyday activities & $4.733^{* *}$ & $2.585-8.669$ & 742 \\
Use alcohol/drugs/ medication to cope & $1.936^{*}$ & $1.027-3.646$ & 742 \\
\hline
\end{tabular}

a. No violence during pregnancy is the reference category with an odds of 1.000 .

b. Includes depression or anxiety attacks, fear, afraid for children, more cautious or aware, sleep problems, shock or disbelief, hurt or disappointment, and upset, confused, or frustrated.

c. Includes ashamed or guilty, lowered self-esteem, problems relating to men, and increased self-reliance.

$* p<.05 ; * * p<.01$

leaving their abusive partner. Past research has reported that pregnant women who are most at risk for homicide may be more likely to leave their partners during their pregnancy (Decker, Martin, \& Morocco, 2004), and it may be that the pregnancy itself motivates some women to leave abusive situations, especially 
if the violence experienced is severe and potentially life threatening or if they fear harm to their unborn child. As well, results in the current study showed that women who experienced violence while pregnant were 5 times more likely to fear that their life was in danger and 7 times more likely not to contact the police because of fear.

Not only were women who experienced violence during pregnancy more likely to report having experienced severe violence but these women also had higher odds of reporting a number of adverse postviolence health effects. Consistent with past research, women experiencing violence during pregnancy were more likely to report physical injury (Bacchus et al., 2006; Martin et al., 2004; Stewart \& Cecutti, 1993), to report various manifestations of psychopathology (Casanueva \& Martin, 2007; Chambliss, 2008; Dunn \& Oths, 2004; Gross et al., 2002; Martin et al., 2006; Pallitto et al., 2005; Valladares et al., 2002), and to use alcohol, drugs, and/or medication to cope with the violence (Datner et al., 2007; Heaman, 2005; Janssen et al., 2003; Lipsky et al., 2005; McFarlane et al., 1996; Pallitto et al., 2005; Stewart \& Cecutti, 1993). These results suggest that women who experience violence during pregnancy are particularly vulnerable to negative physical and mental health effects.

Although the bivariate analyses showed that there were significant differences between victims who had experienced violence during pregnancy and victims who did not experience violence during pregnancy on eight of the independent variables, only verbal abuse and female unemployment were significant predictors of pregnancy violence in the multivariate analysis. Indeed, the risk factors included in the analysis accounted for only about $5 \%$ of the variance in pregnancy violence.

The indications of greater severity and health effects for victims who experienced violence during pregnancy in the current study suggest the possibility that victims who experience violence during pregnancy may be more likely than victims who do not experience violence during pregnancy to be involved with a batterer as opposed to a male partner who engages in less severe and less frequent violence. A growing body of research implicates personality disorders in battering behavior (e.g., Mauricio, Tein, \& Lopez, 2007). Both borderline personality disorder (BPD) and antisocial personality disorder (ASPD) have been linked to battering behavior in past research (e.g., Hamberger \& Hastings, 1986), and it is plausible that the manifestations of these personality disorders may be especially relevant to understanding perpetration of pregnancy violence.

The insecurity, dependency, and emotional volatility associated with BPD may help to explain why some men direct violence toward their pregnant partners. There is some evidence indicating that men who are violent toward their pregnant partners view the unborn child as a direct threat and rival for their partner's attention (Bacchus et al., 2006; Jasinski, 2001; Noel \& Yam, 1992). In addition, these men may be more likely to doubt the paternity of the child (Burch \& Gallup, 2004). Attacks on the woman may represent hostility and ambivalence toward the unborn child, and there is some evidence to suggest that pregnancy violence is often targeted at the abdomen (Bacchus et al., 2006; Pulido \& Gupta, 2002; Stewart \& Cecutti, 1993). ${ }^{7}$ 
Antisocial personality disorder is associated with a lack of empathy and remorse and a "self-centered" approach to life (Hamberger \& Hastings, 1986). Antisocial men are impulsive, aggressive, reckless, irresponsible, and use violence both generally and instrumentally. They are also more likely to use severe forms of violence. The finding in the current study that women who experience violence during pregnancy are more likely to experience severe forms of violence, along with past research that suggests that prepregnancy violence is one of the strongest predictors of pregnancy violence (Dunn \& Oths, 2004; Helton et al., 1987; Janssen et al., 2003; McFarlane et al., 1996; Saltzman et al., 2003; Stewart \& Cecutti, 1993), suggests that some pregnancy violence is a continuation of a pattern of violent behavior that may have been established by personality-disordered men. Indeed, it seems unlikely that men with ASPD would be motivated by pregnancy to cease their use of violence.

The most basic definition of battering refers to "repeated forceful blows" (Dutton, 2006, p. 4). To explore whether battering may be particularly associated with pregnancy violence, an additional logistic regression was run with the verbal abuse and respondent employment variables, along with variables measuring the incidence $^{8}$ and severity of violence ${ }^{9}$ (results not shown). The analysis showed that verbal abuse and respondent's employment were no longer significant predictors of pregnancy violence after the addition of measures of incidence and severity. The more frequently that victims experienced violence, the higher the odds of reporting having experienced violence during pregnancy $(\mathrm{AOR}=1.287, p<.001,95 \% \mathrm{CI}$ $=1.218-1.360$ ). As well, those who experienced severe forms of violence had significantly increased odds of reporting having experienced violence during pregnancy $(\mathrm{AOR}=1.612, p<.05,95 \% \mathrm{CI}=1.033-2.516)$. The Nagelkerke pseudo $R^{2}$ suggested that this model explained $22.9 \%$ of the variance in pregnancy violence. It may be that the importance of verbal abuse and being an unemployed woman in predicting pregnancy violence were connected to an increased likelihood of battering behavior. Indeed, it is possible that verbal abuse and economic subordination are potential warning signs of both battering and pregnancy violence. Moreover, as noted earlier, psychological abuse is used as a means of control, and control is often a key motivation in battering (Pence \& Paymar, 1986).

The current study's results need to be viewed in light of a number of limitations. Although women who had indicated that they had never been pregnant were excluded from the analysis, as noted earlier, it is possible that some women who were coded as having not experienced violence during pregnancy had never been pregnant. Thus, the proportion of victims of pregnancy violence in the current study may be an underestimate because the denominator may have been artificially inflated due to the potential inclusion of women who had never been pregnant. On the other hand, the current study is retrospective, which may produce recall bias. As Gelles (1988) suggests, women who are abused during pregnancy may find this experience so outrageous that the actual events experienced will stand out in their memories, leading to overreporting of pregnancy violence relative to violence not experienced during pregnancy. In addition, though women who reported having experienced violence during pregnancy were more likely to report experiencing each individual form of violence, it cannot be de- 
termined with the available data which specific types of violence occurred during pregnancy. Thus, we do not know whether the more severe forms of violence that these women reported having experienced occurred while they were pregnant. Furthermore, the analysis was limited to risk factors available in the data, and several concepts were measured with single-item indicators. Future research needs to comprehensively examine risk factors for pregnancy violence using measures specifically designed for their operationalization. Finally, though the data used in the current study were the only nationally representative data to include the pregnancy variable, these data were from 1993 and so we could not be certain that the data reflected current trends.

As noted earlier, though pregnancy may be a protective factor for many women, it may represent a period of increased risk for others. Future research directed at the nature and patterns of pregnancy violence is warranted to further understand why pregnancy is associated with an increased risk for violence for some women but not others. Most of the existing research concerning pregnancy violence focuses on the perspectives and characteristics of the female victims rather than on the perspectives and characteristics of the male perpetrators (for an exception see Burch \& Gallup, 2004). Few studies have examined the psychosocial correlates of abuse during pregnancy, and even fewer have included characteristics of the male partner in their analyses (Muhajarine \& D'Arcy, 1999). In particular, future research on the etiology of pregnancy violence should include an assessment of male partners' personality disorders.

In conclusion, though it is evident that several risk factors were associated with pregnancy violence, only women's economic dependence and verbal abuse were significant predictors of violent victimization during pregnancy. The addition of controls for the incidence and severity of violence removed the significance of these predictors, suggesting that the importance of female economic dependence and verbal abuse may have been because they were markers of battering. Service providers, including health care professionals, need to be aware of the issues surrounding pregnancy violence and have the ability to provide pregnant women with the resources and information necessary to ensure their safety. If future research shows that pregnant women are at particular risk of battering, then efforts to address pregnancy violence will need to ensure that the underlying dynamics of battering are addressed, including the assessment of and treatment for ASPD and $\mathrm{BPD}$ among perpetrators of pregnancy violence. Research suggests that violence during pregnancy may be more common than many conditions for which pregnant women are routinely screened or evaluated, including preeclampsia, placenta previa, and gestational diabetes (McFarlane et al., 1996), yet many women are not screened for violence during pregnancy (Shaw, 2003). Although there is some debate over the utility of universal screening for IPV in pregnant women, given the severity and consequences of violence reported by women who have experienced violence during pregnancy, it is evident that efforts such as universal screening of pregnant women each time they enter into prenatal care are warranted.

\section{Notes}

1. Although victims who indicated that they had never been pregnant were excluded from the study, the data documentation commented that some women who were never preg- 
nant may have been included among those who indicated that they had never experienced violence during pregnancy.

2. Since the data were not drawn from a simple random sample, it was necessary to weight the data so that the population was adequately represented. In an analysis of a subsample of the data, the weights provided with the data must be rescaled in a manner that preserves the variability of the original weights but that has an average value of 1. This is accomplished by first calculating the average weight for those respondents in the analysis and then dividing each respondent's weight by this average. The resulting weighting factor is used in the analyses.

3. It must be noted that this is an individual-level indicator of patriarchal domination between a couple rather than a measure of patriarchal culture. For further elaboration of this conceptualization of patriarchal domination, readers may wish to refer to Brownridge (2002).

4. It is important to add that several of these variables also speak to abused women's agency in trying to resolve the violence they are experiencing through contacting community resources.

5. The psychopathology and altered psyche variables were constructed based on the conceptualization of Ratner (1998).

6. Since there were a large number of missing cases on the variable measuring violence by a father-in-law, regressions were run with and without this variable. Results were substantively the same and the risk factors explained the same amount of variance with and without this variable, so the decision was made to exclude this variable from the analysis.

7. Other studies have found that violence during pregnancy is most often directed at the head and extremities (Helton, McFarlane, \& Anderson, 1987; McFarlane, Parker, \& Soeken, 1996; Valladares, Ellsberg, Peña, Höberg, \& Persson, 2002).

8. Incidence refers to the frequency with which respondents reported the violence having occurred. For further elaboration on the definition of incidence, interested readers may wish to refer to Brownridge and Halli (1999).

9. The severity variable distinguished between less severe violence (threat, throw, push, grab, shove, slap) and severe violence (kick, bit, hit with fist, hit with something that could hurt, beaten, choked, threatened with knife/gun, sexually assaulted).

\section{References}

Bacchus, L., Mezey, G., \& Bewley, S. (2006). A qualitative exploration of the nature of domestic violence in pregnancy. Violence Against Women, 12, 588-604.

Bohn, D. K., Tebben, J. G., \& Campbell, J. C. (2004). Influences of income, education, age, and ethnicity on physical abuse before and during pregnancy. Journal of $\mathrm{Ob}$ stetrics, Gynecologic and Neonatal Nursing, 33, 561-571.

Brownridge, D. A. (2002). Cultural variation in male partner violence against women: A comparison of Québec with the rest of Canada. Violence Against Women, 8, 87-115.

Brownridge, D.A. (2006). Intergenerational transmission and dating violence victimization: Evidence from a sample of female university students in Manitoba. Canadian Journal of Community Mental Health, 25, 75-93.

Brownridge, D. A. (2008). The elevated risk for violence against cohabitating women: A comparison of three nationally representative surveys of Canada. Violence Against Women, 14, 809-832. 
Brownridge, D. A., \& Halli, S. S. (1999). Measuring family violence: The conceptualization and utilization of prevalence and incidence rates. Journal of Family Violence, 14, 333-350.

Bullock, L. F. C., Mears, J. L. C., Woodcock, C., \& Record, R. (2001). Retrospective study of the association of stress and smoking during pregnancy in rural women. Addictive Behaviors, 26, 405-413.

Burch, R. L., \& Gallup, G. G., Jr. (2004). Pregnancy as a stimulus for domestic violence. Journal of Family Violence, 19, 243-247.

Campbell, J. C. (2002). Health consequences of intimate partner violence. Lancet, 359, 1331- 1336.

Campbell, J. C., García-Moreno, C., \& Sharps, P. (2004). Abuse during pregnancy in industrialized and developing countries. Violence Against Women, 10, 770-789.

Casanueva, C. E., \& Martin, S. L. (2007). Intimate partner violence during pregnancy and mothers' child abuse potential. Journal of Interpersonal Violence, 22, 603-622.

Chambliss, L. R. (2008). Intimate partner violence and its implication for pregnancy. Clinical Obstetrics and Gynecology, 51, 385-397.

Datner, E. M., Wiebe, D. J., Brensinger, C. M., \& Nelson, D. B. (2007). Identifying pregnant women experiencing domestic violence in an urban emergency department. Journal of Interpersonal Violence, 22, 124-135.

Decker, M. R., Martin, S. L., \& Morocco, K. E. (2004). Homicide risk factors among pregnant women abused by their partners: Who leaves the perpetrator and who stays? Violence Against Women, 10, 498-513.

Dunn, L. L., \& Oths, K. S. (2004). Prenatal predictors of intimate partner violence. Journal of Obstetrics, Gynecologic and Neonatal Nursing, 33, 54-63.

Dutton, D. G. (2006). Rethinking domestic violence. Vancouver, British Columbia, Canada: University of British Columbia Press.

Gazmararian, J. A., Lazorick, S., Spitz, A. M., Ballard, T. J., Saltzman, L. E., \& Marks, J. S. (1996). Prevalence of violence against pregnant women. Journal of the American Medical Association, 275, 1915-1920.

Gelles, R. J. (1988). Violence and pregnancy: Are pregnant women at greater risk of abuse. Journal of Marriage and the Family, 50, 841-847.

Gross, K. H., Wells, C. S., Radigan-Garcia, A., \& Dietz, P. M. (2002). Correlates of selfreports of being very depressed in the months after delivery: Results from the Pregnancy Risk Assessment Monitoring System. Maternal and Child Health Journal, 6, 247-253.

Guille, L. (2003). Men who batter and their children: An integrated review. Aggression and Violent Behavior, 9, 129-163.

Hamberger, L. K., \& Hastings, J. E. (1986). Personality correlates of men who abuse their partners: A cross-validation study. Journal of Family Violence, 1, 323-341.

Heaman, M. I. (2005). Relationships between physical abuse during pregnancy and risk factors for preterm birth among women in Manitoba. Journal of Obstetrics, Gynecologic and Neonatal Nursing, 34, 721-731.

Helton, A. S., McFarlane, J., \& Anderson, E. T. (1987). Battered and pregnant: A prevalence study. American Journal of Public Health, 77, 1337-1339.

Janssen, P. A., Holt, V. L., Sugg, N. K., Emanuel, I., Critchlow, C. M., \& Henderson, A. D. (2003). Intimate partner violence and adverse pregnancy outcomes: A population-based study. American Journal of Obstetrics and Gynecology, 188, 1341-1347. 
Jasinski, J. L. (2001). Pregnancy and violence against women: An analysis of longitudinal data. Journal of Interpersonal Violence, 16, 712-733.

Jasinski. J. L., \& Kaufman Kantor, G. (2001). Pregnancy, stress, and wife assault: Ethnic differences in prevalence, severity, and onset in a national sample. Violence and Victims, 16, 219-232.

Leung, T. W., Leung, W. C., Chan, P. L., \& Ho, P. C. (2002). A comparison of the prevalence of domestic violence between patients seeking termination of pregnancy and other general gynecology patients. International Journal of Gynecology and Obstetrics, $77,47-54$.

Leung, W. C., Leung, T. W., Lam, Y. Y. J., \& Ho, P. C. (1999). The prevalence of domestic violence against pregnant women in a Chinese community. International Journal of Gynecology and Obstetrics, 66, 23-30.

Leung, W. C., Wong, Y. Y. M., Leung, T. W., \& Ho, P. C. (2001). Pregnancy outcomes following domestic violence in a Chinese community. International Journal of Gynecology and Obstetrics, 72, 79-80.

Lipsky, S., Holt, V. L., Easterling, T. R., \& Critchlow, C. W. (2005). Police-reported intimate partner violence during pregnancy: Who is at risk? Violence and Victims, 20, 69-86.

Martin, S. L., Harris-Britt, A., Li, Y., Moracco, K. E., Kupper, L. L., \& Campbell, J. C. (2004). Changes in intimate partner violence during pregnancy. Journal of Family Violence, 19, 201-210.

Martin, S. L., Li, Y., Casanueva, C., Harris-Britt, A., Kupper, L. L., \& Cloutier, S. (2006). Intimate partner violence and women's depression before and during pregnancy. Violence Against Women, 12, 221-239.

Martin, S. L., Mackie, L., Kupper, L. L., Buescher, P. A., \& Moracco, K. E. (2001). Physical abuse of women before, during, and after pregnancy. Journal of the American Medical Association, 285, 1581-1584.

Martin, S. L., Macy, R. J., Sullivan, K., \& Magee, M. L. (2007). Pregnancy-associated violent deaths: The role of intimate partner violence. Trauma, Violence, \& Abuse (Special Issue, Part I), 8, 135-148.

Mauricio, A. M., Tein, J.-Y., \& Lopez, F. G. (2007). Borderline and antisocial personality scores as mediators between attachment and intimate partner violence. Violence and Victims, 22, 139-157.

McFarlane, J., Campbell, J. C., Sharps, P., \& Watson, K. (2002). Abuse during pregnancy and femicide: Urgent implications for women's health. Obstetrics and Gynecology, 100, 27-36.

McFarlane, J., Parker, B., \& Soeken, K. (1996). Physical abuse, smoking, and substance use during pregnancy: Prevalence, interrelationships, and effects on birth weight. Journal of Obstetrics, Gynecologic and Neonatal Nursing, 25, 313-320.

Mezey, G. C., \& Bewley, S. (1997). Domestic violence and pregnancy: Risk is greatest after delivery [Editorial]. British Medical Journal, 314, 1295.

Muhajarine, N., \& D’Arcy, C. (1999). Physical abuse during pregnancy: Prevalence and risk factors. Canadian Medical Association Journal, 160, 1007-1011.

Noel, N. L., \& Yam, M. (1992). Domestic violence: The pregnant battered woman. Women's Health, 27, 871-884.

Pallitto, C. C., Campbell, J. C., \& O'Campo, P. (2005). Is intimate partner violence associated with unintended pregnancy? A review of the literature. Trauma, Violence, $\mathcal{E}$ Abuse, 6, 217-235. 
Pence, E., \& Paymar, M. (1986). Power and control: Tactics of men who batter. Duluth: Minnesota Program Development.

Pulido, M. L. (2001). Pregnancy: A time to break the cycle of family violence. Journal of Health and Social Work, 26, 120-124. vPulido, M. L., \& Gupta, D. (2002). Protecting the child and the family: Integrating domestic violence screening into a Child Advocacy Center. Violence Against Women, 8, 917-933.

Rådestad, I., Rubertson, C., Ebling, M., \& Hildingsson, I. (2004). What factors in early pregnancy indicate that the mother will be hit by her partner in the year after childbirth? A nationwide Swedish survey. BIRTH, 31(2), 84-92.

Ratner, P. A. (1998). Modeling acts of aggression and dominance as wife abuse and exploring their adverse health effects. Journal of Marriage and the Family, 60, 453-465.

Sales, P., \& Murphy, S. (2000). Surviving violence: Pregnancy and drug use. Journal of Drug Issues, 30, 695-724.

Saltzman, L. E., Johnson, C. H., Gilbert, B. C., \& Goodwin, M. M. (2003). Physical abuse around the time of pregnancy: An examination of prevalence and risk factors in 16 states. Maternal and Child Health Journal, 7, 31-43.

Shaw, D. (2003). "Screening" for domestic violence [Commentary]. Journal of Obstetrics and Gynaecology Canada, 25, 918-921.

Smith, M. D. (1990). Patriarchal ideology and wife beating: A test of a feminist hypothesis. Violence and Victims, 5, 257-273.

Statistics Canada. (1999). 1996 census dictionary: Final edition references (No. 92-351UIE). Ottawa, Ontario, Canada: Minister of Industry.

Stewart, D. E., \& Cecutti, A. (1993). Physical abuse in pregnancy. Canadian Medical Association Journal, 149, 1257-1263.

Straus, M. A. (1979). Measuring intrafamily conflict and violence: The Conflict tactics (CT) scales. Journal of Marriage and the Family, 41, 75-88.

Tiwari, A., Leung, W. C., Leung, T. W., Humphreys, J., Parker, B., \& Ho, P. C. (2005). A randomized controlled trial of empowerment training for Chinese abused women in Hong Kong. British Journal of Obstetrics and Gynaecology, 112, 1249-1256.

Tjaden, P., \& Thoennes, N. (2000). Prevalence and consequences of male-to-female and femaleto- male intimate partner violence as measured by the National Violence Against Women Survey. Violence Against Women, 6, 142-161.

Valladares, E., Ellsberg, M., Peña, R., Höberg, V., \& Persson, L. A. (2002). Physical partner abuse during pregnancy: A risk factor for low birth weight in Nicaragua. Obstetrics and Gynecology, 100, 700-705.

Whitfield, C. L., Anda, R. F., Dube, S. R., \& Felitti, V. J. (2003). Violent childhood experiences and the risk of intimate partner violence in adults: Assessment in a large health maintenance organization. Journal of Interpersonal Violence, 18, 166-185.

Widding Hedin, L. (2000). Postpartum, also a risk period for domestic violence. European Journal of Obstetrics and Gynecology and Reproductive Biology, 89, 41-45.

Wilson, M., Johnson, H., \& Daly, M. (1995). Lethal and nonlethal violence against wives. Canadian Journal of Criminology, 37, 331-361.

Xu, X., Zhu, F., O'Campo, P., Koenig, M. A., Mock, V., \& Campbell, J. (2005). Prevalence of and risk factors for intimate partner violence in China. American Journal of Public Health, 95, 78-85. 


\section{The Authors}

Douglas A. Brownridge, $\mathrm{PhD}$, is professor in the Department of Family Social Sciences at the University of Manitoba. He teaches courses on family violence at the undergraduate and graduate levels. His current research includes a focus on violence against women in vulnerable populations.

Tamara L. Taillieu, MSc, is a graduate student in the Applied Health Sciences degree program at the University of Manitoba. Although concerned with the use of violence in all aspects of family life, her current research focuses on factors contributing to intimate partner violence.

Kimberly A. Tyler, PhD, is professor in the Department of Sociology at the University of Nebraska-Lincoln. She teaches courses on family at the undergraduate and graduate levels. Her research interests include homelessness, child abuse and neglect, victimization, and high-risk behaviors among adolescents and youth.

Agnes Tiwari, PhD, is associate professor and assistant dean in the Li Ka Shing Faculty of Medicine at the University of Hong Kong. She is a nurse-academicresearcher in intimate partner violence prevention and intervention. She attends to the health needs of women in a shelter for abused women, coordinates and teaches undergraduate and graduate courses on family violence, and conducts research in intimate partner violence victimization among Chinese women. Her current research focuses on the evaluation of interventions for abused Chinese women.

Ko Ling Chan, PhD, is assistant professor of social work at the University of Hong Kong. He has established his expertise in the area of family violence and has conducted research on a variety of topics, including pregnancy and violence, international dating violence, spousal and child abuse in Hong Kong, and validation of risk assessment tools. He is directing a study of domestic violence costs and a study of child sexual abuse in China.

Susy C. Santos, $\mathrm{PhD}(\mathrm{c})$, is director of the Victoria Institute of Clinical Research and Evaluation (VIC R\&E). Her interdisciplinary program focuses on mental health, geriatrics, gynecology, and violence against women. 